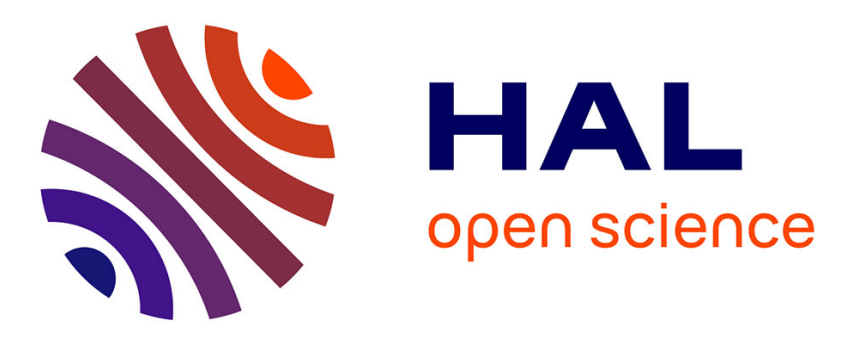

\title{
N3 sleep with rapid eye movements in a PCDH19 mutation: a new dissociate state between N3 and REM sleep \\ Maïlys Rupin-Mas, Isabelle Gourfinkel-An, Isabelle Arnulf
}

\section{- To cite this version:}

Maïlys Rupin-Mas, Isabelle Gourfinkel-An, Isabelle Arnulf. N3 sleep with rapid eye movements in a PCDH19 mutation: a new dissociate state between N3 and REM sleep. Sleep Medicine, 2020, 74, pp.341-342. 10.1016/j.sleep.2020.07.047 . hal-03479253

\section{HAL Id: hal-03479253 \\ https: / hal.sorbonne-universite.fr/hal-03479253}

Submitted on 14 Dec 2021

HAL is a multi-disciplinary open access archive for the deposit and dissemination of scientific research documents, whether they are published or not. The documents may come from teaching and research institutions in France or abroad, or from public or private research centers.
L'archive ouverte pluridisciplinaire HAL, est destinée au dépôt et à la diffusion de documents scientifiques de niveau recherche, publiés ou non, émanant des établissements d'enseignement et de recherche français ou étrangers, des laboratoires publics ou privés. 


\section{N3 sleep with rapid eye movements in a PCDH19 mutation:}

\section{A new dissociate state between N3 and REM sleep}

Maïlys RUPIN-MAS, MD ${ }^{1,2}$, Isabelle GOURFINKEL-AN, MD ${ }^{3}$ and Isabelle ARNULF, $\mathrm{MD}, \mathrm{PhD}^{2}$

1 Child Neurology Department, Angers University Hospital, Angers, France

2 Sleep Disorders Unit, Pitie-Salpetriere Hospital, AP-HP Sorbonne, Paris, France

3 Epilepsy Unit, Neurology department, Reference Center for Rare Epilepsies, PitieSalpetriere Hospital, AP-HP Sorbonne, Paris, France

Corresponding author: Isabelle Arnulf, Service des pathologies du Sommeil, Hôpital Pitié-Salpêtrière, 47-83 boulevard de l'Hôpital 75013 Paris, France

Phone: 33 142167702/04

Fax: 33142167700

e-mail : isabelle.arnulf@aphp.fr

Article submitted to: Sleep Medicine journal

Type of article: Images in Sleep Medicine, Version \# 2

Keys words: dissociate sleep stages, epilepsy, rapid eye movements, PCDH19 mutation

Conflict of interest: the authors report no conflict of interest relative to this topic and case. 


\section{Introduction}

A 28-years-old woman underwent a sleep study, as she complained of prolonged nocturnal awakenings. She suffered from a rare form of epilepsy, caused by a PCDH19 gene mutation. The PCDH19 gene is located in chromosome X. It encodes a calciumdependent cell-adhesion protein from the protocadherin family. Its expression was detected in developing and mature human central nervous system, mainly in the hippocampus and the cortex [1]. She had clusters of focal complex seizures, having started when she was 13-months-old, associated with cognitive and behavioral impairment. At adult age, the epilepsy was controlled by levetiracetam $250 \mathrm{mg}$ twice a day. She took no other drug.

\section{Image analysis}

N3 with REMs: On polysomnography, the last episode of NREM N3 sleep was abnormal (Supplementary Fig.1). The slow wave activity characteristic of N3 stage on the EEG was surprisingly associated with rapid eye movements (which had the sharp onset characteristic of REM sleep eye movements). The concomitant chin EMG showed muscle atonia and rare twitches (as in normal REM sleep). The respiratory and cardiac rhythm and amplitude were regular (as in normal N3 stage). The other sleep stages were normal (no REM sleep behavior disorder, no epileptic activity), except that the EEG during REM sleep contained slower theta activities than usual at this age (Supplementary Fig. 2). From top to bottom: EOG-R and EOG-L, right and left electro-oculogram; F3-A2, C3-A2, O1-A2, EEG channels; chin, mentalis muscle; ECG, electrocardiogram; oral thermistor; airflow, nasal pressure; thorax and abdomen 
inductance plethysmography; Pulse plethysmography. The green arrows indicate rapid eye movements.

\section{Discussion}

State dissociations are described between wake and REM sleep (sleep paralysis, hypnagogic hallucinations, REM sleep behavior disorder, lucid dreaming) and between wake and NREM sleep (sleepwalking, sleep terrors, confusional arousal). The extreme expression of state dissociation is status dissociatus [2].

Intrusions of REM sleep features (as observed here) into NREM sleep are rarer. Phasic muscle activity during NREM sleep has been observed in some patients with synucleinopathies, consisting mostly in sudden trunk and limb jerks and more complex motor behaviors in $\mathrm{N} 1$ and $\mathrm{N} 2$ sleep $[3,4]$. Slow rolling and mildly sharp eye movements can contaminate N2 sleep when patients are treated with anti-depressants ("Prozac eyes"). We are not aware of previous reports of N3 with REMs. This case suggests a transient inability to activate the cortical EEG when the other REM sleep features (REMs, muscle atonia and twitches) have already appeared, possibly combined with the abnormal persistence of delta waves in the end of the night. Here, the dissociate stage occurred only during the last N3 stage, at 5 PM, when slow wave activity, which should follow a progressive decay across the night, did not (Supplementary Fig.1). This may contribute to disfacilitate cortical activation. In animal models, the cortex is activated during REM sleep via a cholinergic network originating from the pedunculopontine nucleus/laterodorsal tegmentum nucleus, and projecting to the intralaminar nuclei of the thalamus [5]. 
The role of PCDH19 gene is yet unknown, but another protocadherin (PCDH10) is required for the growth of the thalamocortical projections. One may wonder whether the impaired cortical activation in REM sleep and N3 sleep (found incidentally here, as sleep in PCDH19 has not yet been described) is linked to an abnormal brain networking of the cholinergic arousal system, which could in its turn affect the REM sleep associated cognitive functions.

\section{References}

[1] Dibbens LM, Tarpey PS, Hynes K, et al. X-linked protocadherin 19 mutations cause female-limited epilepsy and cognitive impairment. Nat Genet 2008;40:77681.

[2] Mahowald MW, Schenck $\mathrm{CH}$. Dissociated states of wakefulness and sleep. Neurology 1992;42:44-52.

[3] Miguel R, Arnulf I. Phasic activity during non REM sleep. Sleep Med 2017; 29:3740.

[4] Fernandez-Arcos A, Morenas-Rodriguez E, Santamaria J, et al. Clinical and videopolysomnographic analysis of rapid eye movement sleep behavior disorder and other sleep disturbances in dementia with Lewy bodies. Sleep 2019; 42.

[5] Saper CB, Fuller PM. Wake-sleep circuitry: an overview. Curr Opin Neurobiol 2017; 44, 186-192. 
Supplemental Figure \#1: From the top to the bottom: Hypnogram showing the sleep stages, including REM sleep (R) wakefulness (W), N1, N2 and N3 stages of NREM sleep, across clock time. Below is the spectral power analysis of F3 EEG, to illustrate the power of slow wave activity, in blue, followed by the presence and density of rapid eye movements (REMs) in the last box. The blue arrow indicates the N3 phase containing REMs.

\section{Supplemental Figure \#2:}

Polysomnography aspects of wakefulness (W), N2 sleep and REM sleep in the same patient. From top to bottom: EOG-R and EOG-L, right and left electro-oculogram; F3A2, C3-A2, O1-A2, EEG channels; chin, mentalis muscle; EKG; naso-oral thermistor; nasal pressure; thorax and abdomen inductance plethysmography; Pulse plethysmography. The green arrows indicate rapid eye movements. 


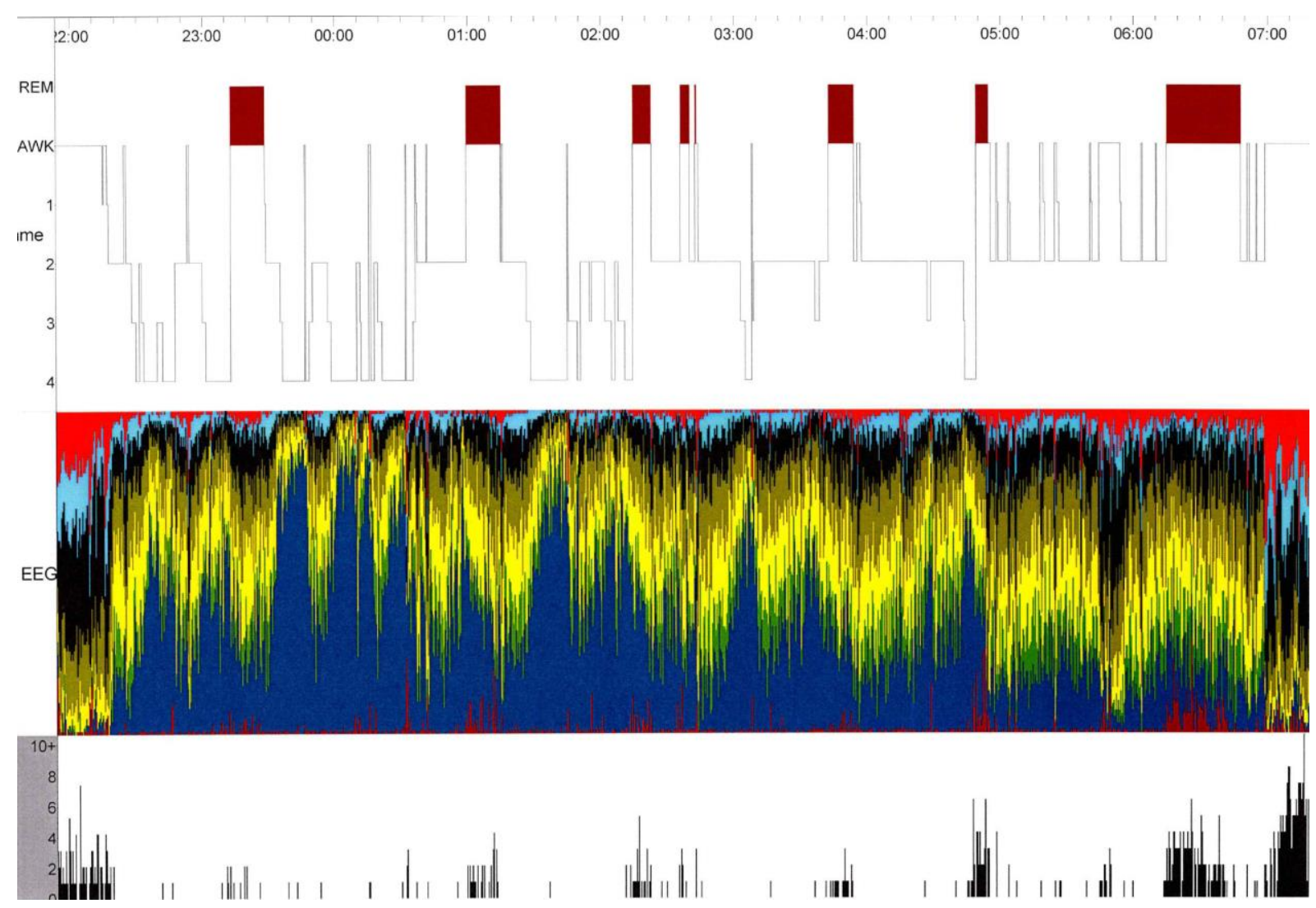

